\title{
Molecular Docking of Natural Compounds from Tulsi (Ocimum sanctum) and neem (Azadirachta indica) against SARS-CoV-2 Protein Targets
}

\author{
Arun HS Kumar*
}

\begin{abstract}
Background: Antiviral activity of tulsi and neem extracts are widely reported. Selected natural compounds from tulsi and neem were hence screened for their efficacy against SARS-CoV-2 targets. Materials and Methods: Using molecular docking tools, the binding efficacy ofnatural compounds from tulsi and neem were tested against three key SARS-CoV-2 targets i.e., 1) surface glycoprotein (6VSB) responsible for viral attachment, 2) RNA dependent RNA polymerase $(6 \mathrm{M} 71)$ responsible for viral replication and 3) main protease (6Y84) responsible for viral replication. Results: Methyl eugenol, oleanolic acid and ursolic acid had high binding efficacy against surface spike glycoprotein and RNA polymerase of SARS-CoV-2. Epoxyazadiradione, Gedunin, Methyl eugenol, Oleanolic acid and Ursolic acid showed high binding efficacy against the main protease of SARS-CoV-2. Binding efficacy of natural compounds from tulsi and neem was superior to that of the standard drugs Lopinavir/Ritonavir and Remdesivir. Conclusion: Natural compounds from tulsi and neem have high binding efficacy against SARS-CoV-2 targets involved in viral attachment and replication, hence will be useful in the management of infection caused by SARS-CoV-2.
\end{abstract}

Key words: Protease inhibitors, RNA polymerase inhibitors, Coronavirus, Covid-19, Antiviral drugs, SARS-CoV-2, Viral entry, Glycoprotein.

\section{INTRODUCTION}

SARS-CoV-2 is a new strain of coronavirus, first reported from the Wuhan region of China. ${ }^{1-3}$ The illness caused by SARS-CoV-2 is referred to as Covid-19, ${ }^{4-6}$ which in its pandemic form has lockdown the world resulting in serious health, social and economic setbacks. The lack of any effective drugs or vaccines to prevent or treat Covid-19 remains a major constraint in removing the lockdown set worldwide. Hence effective cure or prevention measures against Covid-19 is been actively explored.

In the Indian traditional healthcare system, several plant extract are used for the treatment of viral infections. ${ }^{7}$ Among these plantstulsi (Ocimum sanctum) $)^{8,9}$ and neem (Azadirachta indica) $)^{10,11}$ are widely used to treat viral infections in humans and animals due to their antimicrobial and immunostimulant properties. Tulsi and neem are known to have several types of natural compounds with varying medicinal properties. ${ }^{8-11}$ In this study the efficacy of some selected compounds from tulsi and neem were screened using in silco pharmacology against three SARS-CoV-2 specific targets (6VSB: Surface spike glycoprotein; 6M71: RNA dependent RNA polymerase and 6Y84: Main Protease).

\section{MATERIALS AND METHODS}

The 3D structure of SARS-CoV-2 targets \{surface glycoprotein (6VSB), RNA dependent RNA polymerase (6M71) and main protease (6Y84) $\}$ were downloaded as PDB files from the protein data bank (https://www. rcsb.org/) and were optimized for molecular docking in the Chimera software. ${ }^{12}$

The selected structures of natural compounds in tulsi (Rosmarinic acid, Oleanolic acid, Ursolic acid and Methyl eugenol) and neem (Azadirachtin, Nimbin, Epoxyazadiradione and Gedunin) were accessed from PubChem database and were converted to PDB file format and minimised for molecular docking using the Chimera software. ${ }^{12,5}$ Allicin was used as a negative control. Lopinavir/Ritonavir, STGYC and Remdesivir were used as the positive control against the viral protease, surface glycoprotein and RNA Polymerase respectively.Molecular docking was performed to evaluate the binding efficacy of these compoundsagainst the SARS-CoV-2 targets using AutoDock Vina and the docked protein-ligand complex were visualised using the Chimera and PyMOL v 1.8.2.0 software. ${ }^{12-15}$

\section{RESULTS}

Among the compounds tested, methyl eugenol, oleanolic acid and ursolic acid had the highest binding 
efficacy against both surface spike glycoprotein and RNA polymerase of SARS-CoV-2 (Table 1 and 2). All these compounds showed better efficacy than the positive control (STGYC and Remdesivir). Several of the natural compounds from tulsi and neem had high binding efficacy against the main protease of SARS-CoV-2 (Table 3). Gedunin showed the highest binding efficacy against the main protease. Interestingly all the compounds from tulsi and neem were superior to the binding efficacy of Lopinavir/Ritonavir. The natural compounds in their different confirmations were observed to be binding to different regions of the surface spike glycoprotein (Figure 1) and RNA polymerase (Figure 2), while these compounds were bound to a single region of the main protease (Figure 3).

Table 1: Binding efficacy of natural compounds from Tulsi and Neem against surface spike glycoprotein (6VSB) of SARS-CoV-2.Compounds showing high efficacy are highlighted.

\begin{tabular}{|cccc}
\hline & $\begin{array}{c}\text { Affinity } \\
\text { (Kcal/mol) }\end{array}$ & Ki $(\mu \mathrm{M})$ & \\
\hline Azadirachtin & $-6.79 \pm 0.51$ & $13.21 \pm 0.65$ & $26.25 \pm 1.33$ \\
\hline Epoxyazadiradione & $-7.74 \pm 0.31$ & $2.36 \pm 0.13$ & $4.71 \pm 0.26$ \\
Gedunin & $-7.78 \pm 0.38$ & $2.27 \pm 0.15$ & $4.53 \pm 0.21$ \\
Methyl eugenol & $-8.29 \pm 0.20$ & $0.87 \pm 0.03$ & $1.74 \pm 0.06$ \\
\hline Nimbin & $-6.53 \pm 0.33$ & $18.22 \pm 0.88$ & $36.51 \pm 1.77$ \\
\hline Oleanolic acid & $-8.27 \pm 0.41$ & $1.02 \pm 0.05$ & $2.04 \pm 0.16$ \\
Rosmarinic acid & $-7.01 \pm 0.43$ & $8.54 \pm 0.43$ & $1.71 \pm 0.08$ \\
\hline Ursolic acid & $-8.37 \pm 0.31$ & $0.79 \pm 0.03$ & $1.59 \pm 0.06$ \\
STGYC & $-5.51 \pm 0.27$ & $9.75 \pm 0.35$ & $195 \pm 7.07$ \\
(+ve Control) & & $5284 \pm 186$ & $10569 \pm 3721$ \\
\hline Allicin (-ve Control) & $-3.14 \pm 0.25$ & &
\end{tabular}

Table 2: Binding efficacy of natural compounds from Tulsi and Neem against RNA dependent RNA polymerase (6M71) of SARS-CoV-2.Compounds showing high efficacy are highlighted.

\begin{tabular}{cccc} 
& $\begin{array}{c}\text { Affinity } \\
(\text { Kcal/mol) }\end{array}$ & Ki $(\mu \mathrm{M})$ & $\mathrm{IC}_{50}(\mu \mathrm{M})$ \\
\hline Azadirachtin & $-6.84 \pm 0.21$ & $9.99 \pm 0.31$ & $20.31 \pm 0.61$ \\
Epoxyazadiradione & $-7.58 \pm 0.42$ & $3.36 \pm 0.20$ & $6.72 \pm 0.39$ \\
Gedunin & $-7.61 \pm 0.15$ & $2.67 \pm 0.07$ & $5.35 \pm 0.13$ \\
Methyl eugenol & $-8.10 \pm 0.25$ & $1.21 \pm 0.04$ & $2.42 \pm 0.07$ \\
Nimbin & $-6.48 \pm 0.49$ & $23.11 \pm 1.62$ & $46.21 \pm 3.24$ \\
Oleanolic acid & $-8.00 \pm 0.28$ & $1.50 \pm 0.08$ & $2.99 \pm 0.15$ \\
Rosmarinic acid & $-6.59 \pm 0.34$ & $16.70 \pm 0.84$ & $33.40 \pm 1.67$ \\
Ursolic acid & $-8.01 \pm 0.31$ & $1.47 \pm 0.07$ & $2.94 \pm 0.13$ \\
Remdesivir & $-7.69 \pm 0.29$ & $2.52 \pm 0.12$ & $5.05 \pm 0.24$ \\
(+ve Control) & & $8990 \pm 256$ & $17980 \pm 5127$ \\
Allicin (-ve Control) & $-2.81 \pm 0.17$ & &
\end{tabular}

Table 3: Binding efficacy of natural compounds from Tulsi and Neem against main Protease (6Y84) of SARS-CoV-2. Compounds showing high efficacy are highlighted.

\begin{tabular}{|cccc}
\hline & $\begin{array}{c}\text { Affinity } \\
(\text { Kcal/mol })\end{array}$ & Ki $(\mu \mathrm{M})$ & $\mathrm{IC}_{50}(\mu \mathrm{M})$ \\
\hline Azadirachtin & $-7.72 \pm 0.82$ & $4.69 \pm 0.59$ & $9.38 \pm 0.12$ \\
Epoxyazadiradione & $-8.27 \pm 0.75$ & $1.47 \pm 0.14$ & $2.94 \pm 0.28$ \\
Gedunin & $-9.40 \pm 0.61$ & $0.17 \pm 0.01$ & $0.35 \pm 0.02$ \\
Methyl eugenol & $-8.89 \pm 0.51$ & $0.39 \pm 0.03$ & $0.79 \pm 0.06$ \\
Nimbin & $-7.23 \pm 0.52$ & $7.38 \pm 0.84$ & $14.81 \pm 1.69$ \\
Oleanolic acid & $-8.95 \pm 0.46$ & $0.33 \pm 0.02$ & $0.67 \pm 0.03$ \\
Rosmarinic acid & $-7.88 \pm 0.42$ & $2.06 \pm 0.14$ & $4.11 \pm 0.27$ \\
Ursolic acid & $-9.09 \pm 0.47$ & $0.27 \pm 0.01$ & $0.53 \pm 0.03$ \\
Lopinavir & $-6.97 \pm 0.45$ & $9.86 \pm 0.71$ & $19.7 \pm 1.41$ \\
(+ve Control) & & $2427 \pm 562$ & $4855 \pm 1124$ \\
Allicin (-ve Control) & $-3.58 \pm 0.14$ & &
\end{tabular}

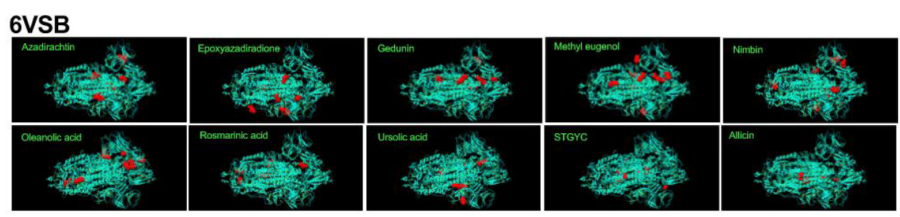

Figure 1: Binding location of various confirmation of natural compounds (red spheres) from Tulsi and Neem against surface spike glycoprotein (6VSB) of SARS-CoV-2.
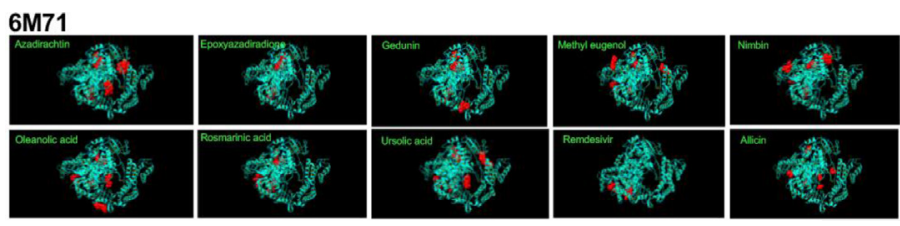

Figure 2: Binding location of various confirmation of natural compounds (red spheres) from Tulsi and Neem against RNA dependent RNA polymerase (6M71) of SARS-CoV-2.

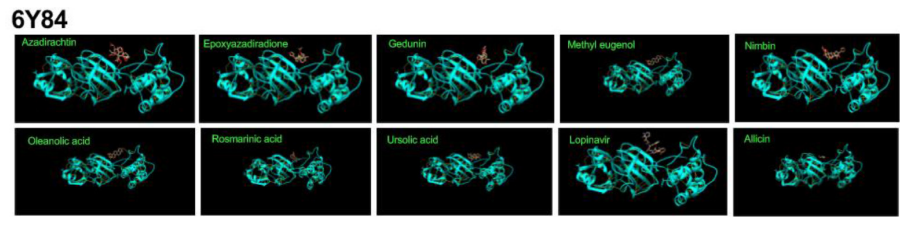

Figure 3: Binding location of natural compounds (ball and stick structure in red) from Tulsi and Neem against main Protease (6Y84) of SARS-CoV-2.

\section{DISCUSSION}

All the natural compounds in tulsi and neem tested in this study had significantly higher or similar binding efficacy against their SARS-CoV-2 targets when compared to the positive controls. 6VSB (surface spikeglycoprotein) is responsible for viral attachment, while 6Y84 (main Protease) and 6M71 (RNA dependent RNA polymerase) areinvolved in viral replication. ${ }^{5,16,17}$ Hence the compounds from tulsi and neem either in their pure form or as an extract of tulsi/neem can be effective inhibitors of SARS-CoV-2 by binding to the spike glycoprotein, RNA polymerase 
and/or its protease.The variations in the binding regions of the natural compounds against SARS-CoV-2 spike surface glycoprotein and RNA polymerase suggests that these compounds will be equally efficacious in preventing both viral attachment and replication. ${ }^{16,18}$ SARS-CoV-2 is reported to have high predilection in the pharyngeal epithelial cells. ${ }^{[17} \mathrm{s}$ the deliverability of tulsi and neem extract to the pharyngeal regions is feasible by suitable oral formulations, they will be useful in the medical management of SARS-CoV-2 infections. The superior binding efficacy of tulsi and neem compounds compared to both Lopinavir/Ritonavir and Remdesivir merits their clinical translation.

\section{ACKNOWLEDGEMENT}

Research support from University College Dublin-Seed funding/Output Based Research Support Scheme (AHSK), Royal Society-UK (AHSK) and Stemcology (AHSK) is acknowledged.

\section{CONFLICT OF INTEREST}

The authors declare no cobflict of interset.

\section{REFERENCES}

1. Fauci AS, Lane HC, Redfield RR. Covid-19 - navigating the uncharted. N Engl J Med. 2020;382:1268-9.

2. Remuzzi A, Remuzzi G. COVID-19 and Italy: What next?. Lancet. 2020.

3. Cucinotta D, Vanelli M. WHO declares COVID-19 a pandemic. Acta Biomed. 2020;91(1):157-60

4. Andersen PI, lanevski $\mathrm{A}$, Lysvand $\mathrm{H}$, et al. Discovery and development of safe-in-man broad-spectrum antiviral agents. Int J Infect Dis. 2020.

5. Kumar AHS, Sharma V. Acetamido-Propanoic Acid Derived Compounds as Protease Inhibitors to Target Coronaviruses. BEMS Reports. 2019;5(2):1-3.
6. Thomson G. COVID-19: Social distancing, ACE 2 receptors, protease inhibitors and beyond?. Int J Clin Pract. 2020;e13503.

7. Muhammad NS, Fiaz R, Asia K, et al. Plant as a Source of Natural Antiviral Agents. Asian Journal of Animal and Veterinary Advances. 2011;6(12):1125-52.

8. Kumar SSG, Srilatha G, Anita C, et al. Ayurveda's Holistic Lifestyle Approach for the Management of Coronavirus disease (COVID-19): Possible Role of Tulsi. Int J Res Pharm Sci. 2020;11:16-8.

9. Ghoke SS, Sood R, Kumar N, et al. Evaluation of antiviral activity of Ocimum sanctum and Acacia arabica leaves extracts against $\mathrm{H}_{9} \mathrm{~N}_{2}$ virus using embryonated chicken egg model. BMC Complement Altern Med. 2018;18(1):174.

10. Badam L, Joshi SP, Bedekar SS. In vitro antiviral activity of neem (Azadirachta indica. A. Juss) leaf extract against group B coxsackieviruses. J Commun Dis. 1999;31(2):79-90

11. Tiwari V, Darmani NA, Yue BY, et al. In vitro antiviral activity of neem (Azardirachta indica L.) bark extract against herpes simplex virus type-1 infection. Phytother Res. 2010;24(8):1132-40.

12. Yang Z, Lasker K, Schneidman-Duhovny D, et al. UCSF Chimera, MODELLER, and IMP: An integrated modeling system. J Struct Biol. 2012;179(3):269-78.

13. O'donoghue SI, Goodsell DS, Frangakis AS, et al. Visualization of macromolecular structures. Nat Methods. 2010;7(3 Suppl):S42-55.

14. Trott O, Olson AJ. AutoDock Vina: Improving the speed and accuracy of docking with a new scoring function, efficient optimization, and multithreading. J Comput Chem. 2010;31(2):455-61.

15. Seeliger $\mathrm{D}$, DeGroot BL. Ligand docking and binding site analysis with PyMOL and Autodock/Nina. J Comput Aided Mol Des. 2010;24(5):417-22.

16. Choy KT, Wong AY, Kaewpreedee $P$, et al. Remdesivir, lopinavir, emetine and homoharringtonine inhibit SARS-CoV-2 replication in vitro. Antiviral Res. 2020;178:104786

17. Stower H. Virological assessment of SARS-CoV-2. Nat Med. 2020;26(4):465.

18. Beck BR, Shin B, Choi Y, et al. Predicting commercially available antiviral drugs that may act on the novel coronavirus (SARS-CoV-2) through a drug-target interaction deep learning model. Comput Struct Biotechnol J. 2020;18:784-90.

Cite this article : Kumar AHS. Molecular Docking of Natural Compounds from tulsi (Ocimum sanctum) and neem (Azadirachta indica) against SARS-CoV-2 Protein Targets. BEMS Reports. 2020;6(1):11-13. 